\title{
Student Attitudes toward Career Counseling Services at Sultan Qaboos University
}

Mahmoud S. AlMa'wali*

Sultan Qaboos University, Sultanate of Oman

\author{
Received: $1 / 5 / 2017$ \\ Accepted: 22/6/2017
}

\begin{abstract}
This study investigated student attitudes toward career counseling services at Sultan Qaboos University (SQU). A total of 134 full-time undergraduate students took part in the study. Using Rochlen, Mohr, and Hargrove's (1999) Attitudes Toward Career Counseling Services (ATCCS) scale, student attitudes were obtained. ATCCS was adapted to Arabic. Reliability scores for the subscales (Value: $\alpha=.83$, Stigma: $\alpha=.70$ ). Both genders indicated moderate to high value for career services, with no significant gender difference. Also, there was no significant gender difference in stigma for seeking career services nor stigma was found. Both genders showed low levels of stigma. There was a negative relationship between value and stigma scales. Results indicated no significant differences due to year in college in levels of value and stigma. Location of the center and marketing of services negatively influenced students' willingness to seek career services. Results are discussed and directions for further research are provided.
\end{abstract}

Keywords: Attitudes, SQU, career counseling, stigma, Oman.

اتجاهات الطلبة نحو خلمات التوجيه الوظيفي يـ جامعة السلطان قابوس

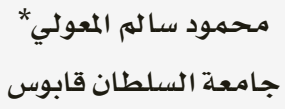

*mawali89@squ.edu.om 


\section{Culture and student university life at SQU}

Oman is an Arab country located in the Middle-East. Like most Arab and Asian cultures, the overarching culture is collectivistic in which the family is the backbone of individuals' lives (Dwairy et al., 2006). Adherence to family rules and making sure that one is in line with family expectations is very crucial to most Omanis (Al-Bahrani, 2004). For instance, middle school students usually spend a considerable time discussing with their families whether to take more arts or life sciences subjects, and usually the decision is a combination of a number of factors such as student academic performance, family opinions, and future prospects of the job market. One study found that permissive and authoritative parenting styles were directly related to academic well-being, indicating a strong parental involvement in academic decision making (Aldhafri, 2011). It is not surprising that university students rely on their personal efforts and family members to help in major choices, with less reliance on professional help seeking.

SQU is currently the only governmental university in Oman. It accepts students from both genders, different SES, and different ability statuses. Male and female students study together in shared classrooms where males usually sit in the front and females prefer sitting at the back of the classroom. Most of the majors at SQU are taught in English, and there are a few majors that are taught in Arabic, such as education and the liberal arts. Most female students live in on-campus dorms while males live out of campus. At SQU, there is a myriad of extracurricular activities where both genders participate in such a way that conforms with the religious and cultural values of the society. Students are assigned to a major once they are admitted to SQU but they are given the opportunity to explore and switch to different majors, particularly during the first 3 years. Therefore, it is not uncommon for SQU students to experience the difficulty of choosing and switching between majors, and they normally do that with the help of their academic advisors.

There is scarce research investing the dynamics of career decision-making among Omani university students. One investigation of help seeking among distressed Omani women in health institutions found that most patients considered cultural beliefs to be a barrier to help seeking, particularly in relation to personal lives; "Some informants explained that it was inappropriate culturally to talk to the doctor about their private lives" (Al-Busaidi, 2010, p.195). A number of studies (e.g., Al-Bahrani. 2004; Al-Darmaki, 2003, 2011a \& 2011b) have been conducted in Oman and United Arab Emirates (UAE) to investigate student counseling services help seeking processes. The studies revealed that seeking professional psychological help among university students was influenced by factors such as family, personal efforts, stigma, culture, and religion. They also indicated a general low attitude towards help seeking due to the influence of the aforementioned factors.

The few available studies revealed that social stigma, cultural beliefs, self-reliance, and family help are among the significant barriers to professional help seeking in Oman. Though both cultures Oman and UAE have some similarities, there is a need for more research pertaining to attitudes toward general and career counseling services in Oman. This also suggests that more research is needed to explore other possible barriers to promote professional seeking among college students. Some of the variables pertain to different types of stigma, outreach strategies, and location of services. More specifically, university student career decision-making can create emotional strain and may lead to poor choices (Zikic \& Saks, 2009).

\section{Importance of professional help seeking}

People seek counseling for a number of reasons, and transition from school to college, in particular, can engender a great deal of anxiety, distress, and homesickness (Berman, and Sperling, 1991; Elzubeir, Elzubeir, and Magzoub, 2010). Many college students come to counseling services for obvious reasons and may discover that other underlying factors are affecting the quality of their lives. College students were reportedly suffering from a number of psychological health problems and considerable distress (Hunt \& Eisenberg, 2010). College life is characterized by important decision-making processes such as choice of a college major, academic performance concerns, and job search skills (Adams, 2012).

Among the significant resources that can help reduce an important aspect of student anxiety is university career services. They are considered among the most crucial services in any 
university (McGrath, 2002). Gobel (2014) explains that enabling students to find decent jobs is the ultimate goal of universities, and university career services play a key role in this effort. According to Fouad et al. (2006), most students face difficulties related to career decisions-making and mental health issues. Student psychological distress was strongly related to career concerns, but only half of students had clear ideas about university career services. Similarly, most of the students seeking career services suffered from psychological distress among other problems (Lucas, and Berkel, 2005).

Examining the economic value of career services among Korean college students, Choi, Lee, Kim, Kim, Cho, and Min Lee (2013) concluded that students were willing to seek individual career counseling even if they had to pay. Despite the various free services offered by university career services, the number of students seeking career services is disproportionate in relation to the total student population (Amrein, 2013).

\section{Attitudes towards help seeking among col- lege students}

Attitudes and beliefs about something are important influencing factors of behavior (Vroom, 1946 as cited in Pinder, 1998). Outcome expectations of a professional help accounted for about $62 \%$ of the reasons college students seek counseling (Vogel, Wester, Wei, \& Boysen, 2005). Vogel et al. argued that the extent students felt they made use of psychological help could predict students' behaviors towards the helping profession. Pheko, Chilisa, Balogun, and Kgathi (2013) similarly examined college students' attitudes towards counseling, and concluded that attitudes towards help seeking were influenced by self and social stigmas. In Oman, Al-Bahrani (2004) investigated the help seeking processes among SQU students, and found that cultural norms and religion were two main factors helping students deal with their psychological problems, particularly in relation to homesickness and academic demands. However, Al-Bahrani asserted that culture and religion were only coping mechanisms, meaning that these two may not always help in adjustment. The study added that SQU students were in need of higher levels of awareness regarding the significance of professional help seeking. In a similar vein, Emirati students' preferences for help seeking were self-reliance, family, and friends. Students believed that those sources were the first help seeking options. Interestingly, academic advisors were considered a priority over professional counselors with regards to help seeking (Al-Darmaki, 2003, 2011a, \& 2011b). In Kuwait, Al-Rowaie (2001) studied attitudes towards help seeking among Kuwaiti university students. Females and students with psychology background had a more positive attitude towards help seeking than male students and other students who did not take psychology courses. Years before that, Soliman (1993) found that "counselors, academic counselors, or social workers are least sought-out for help" (p.77). The general findings were that professional help seeking is not at the core of help seeking processes among Arab university students.

\section{Barriers to help seeking: The role of stigma}

The role of family and cultural values are among factors influencing help seeking practices (Kim, and Omizo, 2003, Al-Bahrani, 2004, \& Al-Darmaki 2011a). Kim and Omizo (2003) found that adherence to the Asian value of self-restraint negatively affected help seeking behaviors among Asian Americans. Asian American students had low attitudes towards counseling as not to show signs of weakness. It is clear that stigma was linked to low motivation towards seeking counseling services. For instance, Ludwikowski et al. (2009) found that self and public stigma discouraged many college students from seeking career counseling. In particular, Vogel, Wade, and Hackler (2007) found that self-stigma influenced students' attitudes towards seeking professional help. Moreover, Pheko et al (2013) reported that college students in Botswana were not as motivated to see a counselor when facing career problems. In a similar study, Miville and Constantine (2007) investigated the reasons why Asian American college girls did not seek counseling during college experience, particularly looking at the influence of the family's collectivistic culture in help seeking. Researchers found that the stigma and values associated with help seeking among Asian families negatively influenced members' intentions toward counseling help seeking. Ludwikowski et al. (2009) investigated the commonalities between personal and career counseling and how attitudes towards each may be different. 
Researchers assumed that the presence of problems and self-disclosure are the main similarities between these two types of counseling, believing that attitudes towards both were quite similar.

Ferrera (2014) studied athlete students' attitudes towards career counseling. Ferrera reported that the general attitude towards career counseling was positive and that females valued career services more than male athletes. Self-stigma played a role in males' lower positive attitude towards career counseling. Schwatken (2014) as well found that career indecision predicted attitudes toward career counseling along with self-stigma. That is, the more undecided students were, the more negative were their attitudes towards career services, with a moderating effect of self stigma. There seems to be general consensus that different barriers to seeking career services and stigma play a role in discouraging students from meeting with a career counselor.

Al-Darmaki (2012) studied Arab students' attitudes, self-esteem, and self-efficacy in relation to career counseling in UAE. Men had generally low attitudes towards career counseling and reported higher stigma levels on ATCCS. On the contrary, unlike students in life sciences, female students in the humanities reported low value for career counseling. More specifically, Arab university students tend to seek other ways other than professional help services due to the influence of culture, stigma, and family help patterns (Soliman, 1993). It is obvious that there is interplay among a number of factors that discourage college students from seeking counseling, particularly career counseling services, two of which are social and self-stigmas.

\section{Location of services and facilities}

The Center for Career Guidance at SQU is located in the Annex Administrative building along with other departments. It is located in the eastern part of campus and a little far from colleges such as Arts, Education, Sciences, and Commerce and Political sciences. SQU has a relatively large campus. The center used to be located in the Centers' Complex that was next to two other colleges. According to the National Association for Colleges and Employers NACE (2014), an important standard for college career services centers is accessibility. As stated, "Career services' programs, services, facilities, and resources, including technology, must be accessible to all students" (NACE, 2014 , p. 33). This professional standard implies that the location of the career center in any college has to be within reach of all students so as to meet diverse student conditions. Furthermore, Herr, Rayman, and Garis (1993) indicated that it would not be acceptable that a career center be placed at the outskirts of campus nor feasible to merge career services with mental health clinics. Herr et al. (1993) strongly believed that career services are part of the educational institution and must be appreciated in order to achieve their mission. In a discussion about the emergence of career services centers and their significance, Herr et al. stressed the vital role career services have played in engendering change in students' career development process. According to McGrath (2002), while career services centers used to be hidden and offer a limited number of services for university students, they have become more visible and accessible to students due to their vital role in student career success. McGrath reiterated the fact that career services have been growing in importance and universities should never overlook their significance. For the scope of this paper, it is vital to consider whether career services location might be a considerable barrier to seeking career services, particularly in large university campuses.

\section{Marketing of career services and outreach strategies}

Outreach and marketing strategies are crucial tools for the success of university career and counseling services. Rochlen, Blazina, and Raghunathan (2002) studied the influence of using brochures on students' attitudes and stigma towards career counseling. Rochlen et al. found that males' attitudes and self-stigma towards career counseling were positively influenced by career services brochures. Many students did not make use of career services due to marketing issues, possibly because career centers need to accommodate the needs of a wide range of specializations (McCorkle, Alexander, Reardon, and Kling, 2003). Thus, marketing strategies may not reach all students on campus and that part of the population remains disadvantaged. Moreover, Garver, Spralls III, and Divine (2008) concluded that using a variety of marketing techniques such as text messages and emails, technology-based job search skills workshops, credit courses, and one-to-one services are pivotal to accommodate diverse student popu- 
lations. Grasgreen (2013) discussed that career services need to be decentralized in that they reach students at different locations on campus. In other words, centralized career services are among the reasons students are underserved. Finding ways to get more students into career services should be driven by meeting the needs of diverse student populations (Divine, 2008). In a nutshell, marketing services in ways that attract all student majors positively impacts students' use of career services.

\section{Significance and hypotheses}

There is scarce research on the reasons SQU students seek career guidance and the possible factors preventing many of them from seeking services from the Center for Career Guidance. Al-Bahrani (2004) found that SQU students were not generally motivated to seek professional help due to religious and cultural variables in problem conceptualization and solving. AL Ghanboosi (2013) examined students' attrition rates and concluded that many students left SQU due to academic and social factors such that created an inability to meet the demands of a major, being uninterested in one's major, or family circumstances. This study implies that career counseling services at SQU may have played a role in decreasing student attrition rates at SQU. Cueso (2005 as cited in Ludwikowski et al. 2009) and Schwatken (2014) underscored the importance of using career services in reducing student academic indecisiveness as well as attrition. McGarth (2002), McCorkle (2003), Amrein, (2013), Schwatken (2014) asserted that not many students made use of career services, which influenced students' ability to be decided on a major and be more prepared for future job seeking.

The current study aimed to explore SQU students' attitudes toward career guidance services provided by SQU's Center for Career Guidance and the mediating role of stigma. Other related factors in relation to the center's outreach strategies and location of the center on campus were investigated. Our hypothesis were that males had lower levels of value and higher levels of stigma attached to career services (Al-Darmaki,, 2012, 2011a, Fabio and Bernaud, 2008). On the other hand, females have higher levels of value and lower levels of stigma attached to seeking career services at
SQU. In addition, year at college would be an influential factor in the value and stigma levels. The older the student and more advanced in his/her studies, the higher value for and the lower stigma attached to career services are (Fabio \& Bernaud, 2008). In addition, sciences students would have higher attitudes towards CS than humanities students (Al-Darmaki, 2003, 2011a, 2011b, \& 2012).

Moreover, it was hypothesized that location and outreach strategies discouraged SQU students from seeking help from the Center for Career Guidance. Results of this paper could be informative and may help in revisiting strategies implemented to get more clients/students make use of career guidance services at SQU. Learning about students' perceptions and attitudes would help identify issues involved and clarify any ambiguities preventing from utmost use of the center's career services.

\section{Method}

\section{Participants}

The study was conducted at SQU, the largest university in Oman with a total enrollment of about 15,000 full time undergraduate and graduate students. 134 SQU full-time undergraduate students $(\mathrm{N}=54 ; 40 \%$ are males and $\mathrm{N}=80 ; 60 \%$ are females) with 56 students from sciences colleges and 78 from humanities participated in the study. Participants mostly ranged between second to fourth year students. The sample age ranged between 18 to 23 years old. All participants were national Omani students. Courses were identified by contacting the instructors in advance so as to ensure willingness and need for scale translation into Arabic.

\section{Instrument}

The instrument was used to answer the main study question. Rochlen's et al. (1999) Attitudes toward Career Counseling Services (ATCCS) was used to investigate students' attitudes and stigma towards career services. ATCCS is a 16-item scale with two subscales: items 1-8 for value of career counseling (e.g., "Career counseling is a valuable resource in making a career choice") and items 9-16 for stigma toward career counseling (e.g., "I would be too embarrassed to ever schedule an appointment with a career counselor"). The scale is a 4-point-type Likert scale where 
1=strongly disagree, 2=disagree, 3=agree, and $4=$ strongly agree. The subscales can be referred to as $\mathrm{VCC}=$ value of career counseling, and $\mathrm{SCC}=$ stigma toward career counseling. Low scores on VCC mean low value for career counseling and high scores on SCC indicate high stigma towards career counseling. The ATCCS was used by several researchers on different cultural university populations such as Rochlen et al. (1999), Rochlen and O'Brian (2002), Fabio and Bernaud (2008), Al-Darmaki (2012), and Nam, and Park (2015). The validity of the scale is well-established due to its wide use in the career counseling literature. Rochlen et al. (1999) reported 0.85 as reliability for value, and 0.80 for stigma, with a total 0.80 for both subscales. Nam, and Park (2015) reported high construct validity for ATCCS and a reliability level (Cronbach's alpha) 0.87. Fabio and Bernaud (2008) reported $a=.82$ for value and $\alpha=.75$ for the stigma scale. In a translated version to Arabic, Al Darmaki (2012) reported an $\alpha=.80$ and an $\alpha=.78$ for the value and stigma subscales, respectively. Overall, a number of studies support the validity and reliability of the ATCCS. To the author's knowledge, this scale has never been applied to investigate Omani students' attitudes towards career counseling services. Due to unavailability of the translated version by AL-Darmaki (2012), ATCCS was translated into Arabic by the researcher and was then translated back to English by another bilingual person to control for language discrepancies. No significant differences were found when the back translation was compared to the original scale. Some statements in relation to the center's location, outreach and marketing services were separately investigated along with to ATCCS to explore any external factors. Permission to use the scale was obtained and instructions provided for taking the scale were included in the instruction part of the scale.

\section{Procedure}

Students' responses were collected through classroom visits. The instrument was distributed to students psychology courses at Sultan Qaboos University from summer of 2015 to fall of 2016. This was due to moderate response pool when using online surveys sent through the email. Thus, coordination with the professors was arranged in advance to allocate about the first 15 minutes of class time to fill the ATCCS scale and the separately added qualitative statements. Each student received a packet containing a cover sheet (describing the research, confidentiality, and rights) and a paper and pencil instrument. Careful consideration was followed during recruitment so that respondents felt emotionally and academically safe, all the while using a reliable instrument to measure students' attitudes towards career counseling services. The investigator spent a few minutes to introduce the research and to familiarize participants with the scale. Participants were requested to candidly respond to all statements regarding career services at SQU even if they lacked information about some questions. Student participation was voluntary and they were given the choice of not participating if they wished. After taking the instrument, participants were debriefed about the use of the results, their use for students and university, and information about contacting the investigator to learn about the final findings.

\section{Results}

\section{Quantitative Results}

The reliability scores of the ATCCS scale were obtained. The value scale had an alpha internal consistency of .825 , and the Stigma subscale scored had an alpha of .701. Levene's test for equality of variances showed that the sample was homogenous across the value, stigma, and overall.

Table 1 Correlations (Value, Stigma, \& Overall)

\begin{tabular}{lcrr}
\hline & Value & Overall & Stigma \\
\hline Value & 1 & & \\
Overall & $.657^{* *}$ & 1 & \\
Stigma & $-.175^{*}$ & $.626^{* *}$ & 1 \\
\hline${ }^{*} \mathrm{p}<.05,{ }^{* *} \mathrm{p}<.01$ & & &
\end{tabular}

Table 1 shows the Pearson correlation coefficients for the Value, Stigma, and overall Mean. Results show that both subscales (value and stigma) had a significant negative relationship $(r=-.175, \mathrm{p}<.05)$. Results indicated that responses in one scale can be predictive of the other subscale. For example, high scores in the value subscale indicated low scores across the stigma subscale. On the contrary, low scores across the stigma scale meant high scores across the value scale. This shows that stigma may be attached to career help seeking if the value for career services was low. In other words, predicting the level of value attached to career help seeking could be achieved by learning about the level of stigma towards career counseling. Moreover, it is important to 
note that both scales had a positive significant relationship with the overall score of the scale $(a=.000)$. This finding provides further support to previous literature that reported high internal consistency scores for the ATCCS.

Table 2 shows the value of career services among males and females at SQU. One-Way ANOVA demonstrated relatively high mean scores on the value scale for both males and females. In fact, across most value statements, means were higher the test value $(M=2)$, which indicated no gender difference $(t=$ $.263, p>.10)$ for the value of career guidance services at SQU. This is counter to the study's original hypothesis where females were expected to have higher value and lower stigma towards career services. The hypothesis was rejected as no gender difference was found. These results were inconsistent with similar studies such as Rochlen et al. (1999) and AlRowaie (2001) who found that Kuwaiti female university students were more willing to seek career services than males. Moreover, the current results were counter to Al-Darmaki (2012) who found that Emirati female students in humanities colleges had low value for career services. However, the current findings are cosistant with Blondeau and Awad (2017) who found no significant sex differences in help seeking behaviors. They reported "Our findings indicate that the social stigma against seeking help may be reduced in male-oriented domains for males" (p. 183).
As for the stigma subscale, the reported mean across both genders was lower than the test value $(\mathrm{M}=2, \mathrm{t} \geq .717, p>.05)$. The hypothesis was that males had higher levels of stigma attached to seeking career services at SQU than females. The hypothesis was rejected since both males $(M=1.92)$ and females $(M=$ 1.85) scored low levels of stigma attached to career services. This finding was counter to AlBusaidi (2010) who concluded that Omani female patients tended to avoid talking about their personal issues with physicians. This finding was also counter to Fabio and Bernaud (2008) and Al-Darmaki (2012) who reported gender differences in stigma level. With regards to career services, it appears that both genders in Oman may be willing to seek career help when provided or needed, possibly due to previous positive exposure to career guidance at schools (Bernaud \& Bideault, 2005).

Table 3 shows results comparing the effect of major (science versus humanities) on attitudes towards career help seeking. Across the value subscale, no academic major difference was reported, with $M=3.29$ for sciences and $M=$ 3.20 for humanities ( $p>0.05)$. Similarly, Both sciences and humanities students had a relatively low stigma scores (Sciences $\mathrm{M}=1.95$, $\mathrm{SD}=.49$ \& Humanities $\mathrm{M}=1.88, \mathrm{SD}=.50, \mathrm{p}$ $>.05)$. Across both subscales, no significant difference was found in favor of hard sciences majors as in Al-Darmaki (2012).

Table 2

One Way ANOVA (Gender differences across value, Stigma, and Overall)

\begin{tabular}{|c|c|c|c|c|c|c|c|c|}
\hline & Variable & $\mathrm{N}$ & Mean & Std. Deviation & Sum of Squares & $\mathrm{df}$ & Mean Square & $\mathrm{F}$ \\
\hline \multirow[t]{3}{*}{ Value } & male & 54 & 3.2288 & .55586 & .019 & 1 & .019 & $.069 \mathrm{~ns}$ \\
\hline & female & 80 & 3.2531 & .50118 & 36.219 & 132 & .274 & \\
\hline & Total & 134 & 3.2433 & .52198 & 36.238 & 133 & & \\
\hline \multirow[t]{3}{*}{ Stigma } & male & 54 & 1.9259 & .57591 & .143 & 1 & .143 & $.567 \mathrm{~ns}$ \\
\hline & female & 80 & 1.8594 & .44534 & 33.247 & 132 & .252 & \\
\hline & Total & 134 & 1.8862 & .50105 & 33.389 & 133 & & \\
\hline \multirow[t]{3}{*}{ Mean } & male & 54 & 2.5756 & .34555 & .012 & 1 & .012 & $.111 \mathrm{~ns}$ \\
\hline & female & 80 & 2.5563 & .31940 & 14.388 & 132 & .109 & \\
\hline & Total & 134 & 2.5641 & .32904 & 14.400 & 133 & & \\
\hline
\end{tabular}

Table 3

One Way ANOVA (Humanities, Sciences, \& Overall)

\begin{tabular}{llcrrrrrr}
\hline & Variable & $\mathrm{N}$ & Mean & Std. Deviation & Sum of Squares & df & Mean Square & \multicolumn{1}{c}{ F } \\
\hline Value & Sciences & 56 & 3.2946 & .43721 & .253 & 1 & .253 & $.929 \mathrm{~ns}$ \\
& Humanities & 78 & 3.2065 & .57515 & 35.984 & 132 & .273 \\
& Total & 134 & 3.2433 & .52198 & 36.238 & 133 & .403 & $1.611 \mathrm{~ns}$ \\
\multirow{5}{*}{ Stigma } & Sciences & 56 & 1.9509 & .50378 & .403 & 1 & .250 \\
& Humanities & 78 & 1.8397 & .49711 & 32.987 & 132 & .332 \\
& Total & 134 & 1.8862 & .50105 & 33.389 & 133 & $3.112 \mathrm{~ns}$ \\
& sciences & 56 & 2.6228 & .30432 & .332 & 1 & .107 \\
& Humanities & 78 & 2.5219 & .34140 & 14.068 & 132 & 133 & \\
& Total & 134 & 2.5641 & .32904 & 14.400 & 133 & \\
\hline
\end{tabular}


Table 4

One Way ANOVA Year at college, Value, Stigma, \& Overall

\begin{tabular}{llrrrrrrl}
\hline & Variable & $\mathrm{N}$ & \multicolumn{1}{c}{ Mean } & Std. Deviation & Sum of Squares & df & Mean Square & $\mathrm{F}$ \\
\hline Value & Fr So & 52 & 3.2136 & .63041 & .075 & 1 & .075 & $.274 \mathrm{~ns}$ \\
& Ju Se & 82 & 3.2622 & .44297 & 36.163 & 132 & .274 & \\
& Total & 134 & 3.2433 & .52198 & 36.238 & 133 & & \\
Stigma & Fr So & 52 & 1.9014 & .54813 & .020 & 1 & .020 & $.078 \mathrm{~ns}$ \\
& Ju Se & 82 & 1.8765 & .47202 & 33.370 & 132 & .253 & \\
& Total & 134 & 1.8862 & .50105 & 33.389 & 133 & & \\
mean & Fr So & 52 & 2.5557 & .37160 & .006 & 1 & .006 & $.055 \mathrm{~ns}$ \\
& Ju Se & 82 & 2.5694 & .30127 & 14.394 & 132 & .109 & \\
& Total & 134 & 2.5641 & .32904 & 14.400 & 133 & & \\
\hline
\end{tabular}

Note. Fr So: Freshman, Sophomore; Ju Se: Junior, Senior

The overall level of value for CS was higher than the average test score, test value $=2$. Thus, the hypothesis that humanities having lower attitudes towards help seeking than sciences (Al-Darmaki, 2012) does not seem to be true among the study sample. The hypothesis that sciences students have higher attitudes than humanities is rejected as no significant difference was found ( $p>.05)$. The case may not be the same in Oman as SQU students are basically high achievers and goal oriented, which was found to be positively related to attitudes towards help seeking (Mcllveen, Beccaria, Burton, 2013).

Table 4 shows the effect of year at college on value and stigma towards career services. Students at year two were compared with students at year 4 in college. The hypothesis was that as students progress at college, they gain more desire for career services, have higher value than beginning students, and have lower stigma than newer students at SQU. However, One Way ANOVA examining year at college, value, stigma, and overall showed no significant difference in levels of stigma and value with regards to year at college. The mean $\mathrm{M}=3.21(\mathrm{SD}=.63, p>=.05)$ for second year students and $\mathrm{M}=3.26(\mathrm{std} .=.44, p>.05)$ for $4^{\text {th }}$ year students. This is counter to the original hypothesis, thus, the hypothesis that year at college influenced value for career services was rejected. As for the stigma, no significant influence for year at college on stigma level. Both second year students $(\mathrm{M}=1.9, p>$ $.05)$ and fourth year students $(M=1.87, p=.787)$ showed low levels of stigma towards seeking help from career guidance center. The hypothesis was that stigma would be higher with newer students and lower with higher level students (Fabio and Bernaud, 2008). Therefore, the hypothesis was rejected as year at college did not, in fact, influence students' level of stigma.

\section{Qualitative Results}

In addition to the ATCCS (Rochlen, et al. 1999) scale, three open ended questions were asked in relation to accessibility of location and marketing of services across campus. Analysis of the themes of responses could explain few reasons behind students' responses in the ATCCS scale. When asked about the accessibility of the center and the propriety of the location, only a few students answered it was easy to reach. In fact, most responses explained that the center was located far away from most students and that it was not accessible by a lot of students on campus. Participants explained that the need for transportation and hot weather significantly discouraged students from seeking career services for the Center for Career Guidance. Surprisingly, a number of participants indicated ignorance about the location of the center or that they knew little about its services (Crisan, Pavelea, and Ghimbulut, 2014). This finding goes hand in hand with Al-Bahrani (2004) who found that students confused the role of the Center for Career guidance at SQU. As Al-Bahrani reported, students indicated several roles for the center such as social work, resolution of family issues, and help in academic major change for students in probation. This might indicate the misconnection between the student and the center and how this has created role confusion. While participants valued career services and indicated low stigma levels, they indicated need for career services. Many participants explained that the center's location was far away from students and from where most students do their activities. These results are in line with a number of studies such as McGrath (2002) and NACE (2014) professional standards for university career centers. The current literature supports the fact that career services must be close to students' location of activities in order to reach most students. McGrath explained that university career services need to 
reach out for students in order that centers be as beneficial as possible to most students on campus.

Participants were also asked about the center's marketing and outreach strategies through emails, social media, posters, etc. The majority of the responses explained that the center was not as active in using social media to reach students, except for using emails. A number of participants wished that the career guidance center relied on social media as a powerful tool to reach the maximum number of students on campus. Some participants explained that using emails was not enough as many students did not actually check their emails on a regular basis. McGrath (2002) explained that social media was considered an effective tool to get the message across to as many university students as desired.

\section{Discussion}

The current study aimed to investigate student attitudes toward career services at Sultan Qaboos University while looking at gender differences and possible reasons explaining student responses. Using the ATCCS scale for Rochlen et al. (1999), results of the current study clearly indicated a relatively high value for career services. The findings are counter to Al-Rowaie (2001), Fabio and Bernaud (2008) and Al-Darmaki (2012) who found that help seeking processes and attitudes were generally negative among Emirati university students. Unlike UAE university, SQU is a very selective institution whose students are generally high achievers. It was found that students with high levels of academic achievement had more interest in career help seeking as it is a professional way of obtaining career information (Mcllveen, Beccaria, Burton, 2013). This could also be explained in light of previous students' experience with career counseling at high school (Bernaud and Bideault, 2005). Since career guidance started in Omani schools about a decade ago, most of the participants may have had experience with career guidance in one way or another. Participants could have benefited from career services at schools and possibly made use of the same services at university. The results also indicated no gender difference in value for career services. This was counter to Rochlen et al (1999), Fabio and Bernaud (2008), Al-Darmaki (2012) who reported a gender difference towards value for career services in favor of hard sciences female students. This result could be interpreted in a number of ways. First, it might be due to the nature of the job market between Oman and UAE. Al-Harthi (2011) indicated that Omani students and their families place a great value on landing a job post-graduation, which possibly made Omani students place high value for career help seeking. Second, it could be that psychological help seeking may not have the same level of stigma as career counseling (Herr, Rayman, and Garis, 1993). Thus, SQU male students may have positive attitudes towards career services by differentiating between stigma towards psychological help (AlBahrani, 2004) and career guidance services. While male students significantly valued career services, possible cultural and religious alternatives might be considered when being in a career related problem (Al-Bahrani, 2004). While it should be noted that many of the current findings are counter to some of the previous literature, it should not be dismissed that greater awareness about the importance of career help seeking might be growing due to career guidance movement in Oman.

The current study did not indicate a significant difference in ATCCS scores between students in their first two years and students in their last two years. It was expected that as students get closer to graduation, they get more information about the career center's activities (Crisan, Pavelea, and Ghimbulut, 2014). The current findings did not indicate a difference between levels of value and stigma in relation to year at college. It is possible that many students at SQU become concerned with their career as early as they enter university. This idea was supported by Goetsch, Jordan, Jung, Lampman, Nobbs, and Ruiz (2010) who found that the earlier college students get interested in their careers, the more positive attitudes they develop towards career help seeking.

While there was no clear data about the number of students benefiting from career services at SQU, answers to the open ended questions indicated that the majority of the sample did not seek career help, regardless of the fact that they highly appreciated such a service (Crisan, Pavelea, and Ghimbulut, 2014). It might be that students are using other help resources to resolve their career concerns such as academic advising, reading from the web, social media 
(Crisan, Pavelea, and Ghimbulut, 2014), or that they simply do not resolve their career issues. In addition, although results show low levels of stigma towards career help seeking with no gender difference, students did not indicate seeking career help previously. It seems that finding alternatives for solutions, lacking knowledge, or simply lacking intention might be factors to participants' lack of professional help seeking (Fabio and Bernaud, 2008).

Drawing a link between the results of value scale with the qualitative items asked in a separate section, some explanations could be made. First, most participants explained that the current location of the career services was far away from most student activities. Participants claimed that heat and transportation made the task even more difficult should a student want to visit the career guidance center. Many of them indicated unwillingness to visit the center for the previous reasons. It is interesting to find such a discrepancy between students' value for career services and willingness to visit the center. McGrath (2002) explained that the career services location could be a motivating or a de-motivating reason for students to seek career services. As explained earlier, the current location of the Center for career Guidance at SQU is quite far from student activity center and classes. With the high value for career services indicated by the ATCCS, students could be more willing to see a career staff if the center was located close to students' activities. Second, many participants explained that they did not know where the center was located at and that the center was not active in communicating with student population. While this claim needs to be validated, research supports the effectiveness of social media in reaching diverse student populations (McGrath, 2002; and Crisan, Pavelea, and Ghimbulut, 2014). Many professional university career services rely on social media in reaching the maximum number of student populations. It seems that if the center for career guidance was more active in promoting services and workshops through social media, student would know a lot more about the usefulness of the center for students. In such a digital era, social media is at the core of marketing and communication strategies for a lot of organizations. A career center serves clients the same as a company serves customers. There needs to be marketing of events, workshops, and services through all possible media channels to maximize reach out to the target population.

\section{Limitations}

The current study faced a number of challenges and limitations. First, the limited response pool negatively affected recruitment process. The number of respondents (134) was less than the least desired, which was partly related to difficulty of accessing students in other colleges such as Medicine, Science, and Engineering. Second, the sample was not representative of all SQU population as the number might be disproportionate in comparison to the total SQU student number. Hence, careful interpretation of results should be considered. Results may be more generalizable on the study sample but may yield different results if a larger sample was recruited. Third, the researcher had to translate the original copy of the ATCCS to Arabic since a number of students did not read English very well. The translated version in Al-Darmaki (2012) could not be accessed for extraneous factors. This process took some time to complete so as to ensure accuracy, and it may have affected the overall reliability of the original scale, though subscales showed high reliability scores.

\section{Implications for practice}

The current findings have a number of implications for practice. First, career services staff may have an idea now about the level of student willingness to seek career services at Sul$\tan$ Qaboos University and the level of stigma attached to CS. Moreover, CS staff are informed that regardless of the gender, year at college, or age, the majority of students seem to need more attention from CS as described in the qualitative part of the study. Students need to be more aware of the center's specific periodical and ongoing services. Students specifically indicated that social media could be better utilized to reach the target population. In addition, the majority of the students did not believe that the location of the center was convenient. Thus, the CS center may need to conduct more services where most students are located. For this purpose, the decentralized model of CS is recommended as it could eliminate many of the barriers to seek help (Herr, Rayman, and Garis, 1993). In fact, learning the general attitude to CS may not be enough unless students are really benefiting from the services. Another implication could be that career help seeking mentality needs to be con- 
tinually assessed by respective university departments as this might help in developing plans to improve the services.

\section{Recommendations}

The current study might be the first of its kind in the Omani context. To the investigator's knowledge, attitudes toward career counseling services were not investigated in the Omani context. Therefore, further research is recommended, particularly on external factors such as the role of culture on students' lack of career help seeking. Furthermore, related studies involving larger samples of the university student population may need to be conducted in order to yield more accurate results, such as including students from science, medicine, and business colleges. Research should continue exploring the field of career development in Oman as literature about career development is quite scarce.

\section{References}

Adams, C., M. (2012). Calling and career counseling with college students: finding meaning in work and life. Journal of college counseling, 15 (1), 65.

Al-Bahrani, M. A. (2004). An investigation of the help-seeking process among Omani students at Sultan Qaboos University (Doctoral dissertation, Ohio University).

Al-Busaidi, Z. Q. (2010). A qualitative study on the attitudes and beliefs towards help seeking for emotional distress in Omani women and Omani general practitioners: Implications for post-graduate training. Oman medical journal, 25(3), 190.

Al-Darmaki, F. R. (2012). Relationships between career counseling attitudes and selfesteem and self-efficacy among Emirati university students. Journal of Career Development, 39(2), 143-161. doi:10.1177/0894845310380046

Al-Darmaki, F. R. (2011a). Problems and preferences for source of help among United Arab Emirates University students. International Journal for the Advancement of Counselling, 33(4), 293-308.

Al-Darmaki, F. R. (2011b). Needs, attitudes toward seeking professional help, and preferred sources of help among Emirati col- lege students. Journal for International Counselor Education, 3(1), 5.

Al-Darmaki, F. R. (2003). Attitudes towards seeking professional psychological help: What really counts for United Arab Emirates university students?. Social Behavior and Personality: an international journal, 31(5), 497-508.

Aldhafri, S. (2011). Self-efficacy and physical self-concept as mediators of parenting influence on adolescents' school and health wellbeing. Journal of Psychology in Africa, 21(4), 511-520.

ALGhanboosi, S. S. (2013). Factors influencing students' attrition at Sultan Qaboos University (SQU). Education, 133, (4), 513-524.

Al-Harthi, H. K. (2011). University student perceptions of the relationship between university education and the labour market in Egypt and Oman. Prospects, 41(4),

535-551. doi: 10.1007/s11125-011-9216-4

Al-Rowaie, O. O. (2001). Predictors of attitudes toward seeking professional psychological help among Kuwait university students (Doctoral dissertation, Kuwait University).

Amrein, F. (2013, Oct. 16). Importance of the college career center. College Affordability, 1-1. Retrieved online from:

http:/ / collegeaffordability.com/collegeadmissions/importance-of-the-collegecareer-center /

Atkinson, D. R., Lowe, S., \& Matthews, L. (1995). Asian-American acculturation, gender, and willingness to seek counseling. Journal of Multicultural Counseling and Development, 23(3), 130-138. Doi: 10.1002/j.2161-1912.1995.tb00268.x

Beck, R., Taylor, C., \& Robbins, M. (2003). Missing home: Sociotropy and autonomy and their relationship to psychological distress and homesickness in college freshmen. Anxiety, stress, and coping, 16(2), 155-166. DOI: 10.1080/10615806.2003.10382970

Berman, W. H., \& Sperling, M. B. (1991). Parental attachment and emotional distress in the transition to college. Journal of Youth and Adolescence, 20(4), 427-440. http:/ / doi.org/10.1007/BF01537184 
Bernaud, J., \& Bideault, A. (2005). Le de 'terminants de l'attractivite' face a ' une de marche de conseil en orientation. Carrie’rologie, 10(2), 289-303.

Blondeau, L., \& Awad, G. H. (2017). Sex differences in career guidance of undergraduate math students and the relation to help-seeking behaviors. Journal of Career Development (Sage Publications Inc. $)$, 44(2), 174. doi:10.1177/0894845316642866

Choi, B., Lee, J., Kim, A., Kim, B., Cho, D., \& Lee, S. (2013). The economic value of career counseling services for college students in South Korea. The career development quarterly, 61 (2), p 168-178.

Crişan, C., Pavelea, A., \& Ghimbuluț, O. (2015). A need assessment on students' career guidance. Procedia-Social and Behavioral Sciences, 180, 1022-1029. doi: 10.1016/j.sbspro.2015.02.196

Dwairy, M., Achoui, M., Abouserie, R., Farah, A., Sakhleh, A. A., Fayad, M., \& Khan, H. K. (2006). Parenting styles in Arab Societies: A first cross-regional research study. Journal of Cross-Cultural Psycholo$g y, 37(3), 230-247$.

Elzubeir, M. A., Elzubeir, K. E., \& Magzoub, M. E. (2010). Stress and coping strategies among Arab medical students: towards a research agenda. Education for Health, 23(1), 355. Retrieved online on 21/06/2017 from: http:/ / www.educationforhealth.net/articl e.asp?issn $=13576283$; year $=2010$; volume $=23$; $=1$; page $=355$; epage $=355$; aulast $=$ Elzubeir

Fabio, A., \& Bernaud, J. L. (2008). The helpseeking in career counseling. Journal of $\mathrm{Vo}^{-}$ cational Behavior, 72(1), 60-66.

Ferrera, A. J. (2014). Division I college studentathlete career situation and attitudes toward career counseling (Order No. 3672846). Available from ProQuest Dissertations \& Theses A\&I. (1652478561). Retrieved From:

http:/ / search.proquest.com/docview/165247 8561 ? accountid $=13158$

Fouad N., Guillen, A., Harris-Hodge, E., Henry, C., Novakovic, A., Terry, S., \& Kantamneni, N. (2006). Need, awareness, and use of career services for college students. Journal of career assessment, 14 (4), 407-420.
Garver, M. S., Spralls III, S. A., \& Divine, R. L. (2008). Need-based segmentation analysis of university career services: Implications for increasing student participation. Research In Higher Education Journal.

Gobel, R. (2014, April 22). 5 Reasons Why Career Services Is The Most Important Office On Campus. Forbes Education, 1-1. Retrieved online. From: http:/ / www.forbes.com/sites/reynagobel /2014/04/22/5-reasons-why-careerservices-is-the-most-important-office-oncampus/

Goetsch, D., Jordan, C., Jung, C., Lampman, L., Nobbs, S., \& Ruiz, C. Students' Attitudes, Beliefs and Plans Regarding Career Planning and Post-College Life. Retrieved on 18/06/2017. From http:/ / wp.stolaf.edu/sociology/files/2013 /06/Students\%E2\%80\%99-AttitudesBeliefs-and-Plans-Regarding-CareerPlanning-and-Post-College-Life.pdf

Grasgreen, A., (2013, May 13). Career services must die. Inside Higher Ed. Retrieved online. From:

https://www.insidehighered.com/news/2 013/05/15/career-services-it-now-existsmust-die-new-report-argues

Herr, E. D.; Rayman, J. R., and Garis, J. W. (1993). Handbook for the college and university career center. Westport, Connecticut: Greenwood Press, pp. 49-93. ISBN: 0-31328148-3.

Hunt, J., \& Eisenberg, D. (2010). Mental health problems and help-seeking behavior among college students. Journal of Adolescent Health, 46(1), 3-10.

Kim, B. S., \& Omizo, M. M. (2003). Asian cultural values, attitudes toward seeking professional psychological help, and willingness to see a counselor. The Counseling Psychologist, 31(3), 343-361.

Kim, B. S., \& Omizo, M. M. (2003). Asian cultural values, attitudes toward seeking professional psychological help, and willingness to see a counselor. The Counseling Psychologist, 31(3), 343-361.

Lucas, M. S., \& Berkel, L. A. (2005). Counseling needs of students who seek help at a university counseling center: A closer look at gender and multicultural issues. Journal of College Student Development, 46(3), 251-266. 
Ludwikowski, W. M. A., Vogel, D., \& Armstrong, P. I. (2009). Attitudes toward career counseling: The role of public and selfstigma. Journal of Counseling Psychology, 56(3), 408-416. doi:10.1037/a0016180

McCorkle, D. E., Alexander, J. F., Reardon, J., \& Kling, N. D. (2003). Developing selfmarketing skills: Are marketing students prepared for the job search?. Journal of Marketing Education, 25(3), 196-207.

McGrath, G. L. (2002). The emergence of career services and their important role in working with employers. New Directions for Student Services, 2002, 100, p. 69-83. Retrieved online from:

http://onlinelibrary.wiley.com/doi/10.100 2/ss.71/pdf

McIlveen, P., Beccaria, G., \& Burton, L. J. (2013). Beyond conscientiousness: Career optimism and satisfaction with academic major. Journal of Vocational Behavior, 83(3), 229-236.

https://doi.org/10.1016/j.jvb.2013.05.005

Miville, M. L., \& Constantine, M. G. (2007). Cultural values, counseling stigma, and intentions to seek counseling among Asian American college women. Counseling and Values [H.W.Wilson - EDUC], 52(1), 2.

Nam, S. K., \& Park, H. I. (2015). The construct validity of attitudes toward career counseling scale for Korean college students. Journal of Career Development. Doi:0894845315575735.

National Association of Colleges and Employers. (2014). Professional standards for college and university career services 2014. Retrieved online from: https://www.naceweb.org/knowledge/pr ofessional-standards-for-college-anduniversity-career-services.pdf

Owen, J., Thomas, L., \& Rodolfa, E. (2013). Stigma for seeking therapy: Self-stigma, social stigma, and therapeutic processes. The Counseling Psychologist, 41(6), 857-880. doi:10.1177/0011000012459365

Pheko, M. M., Chilisa, R., Balogun, S. K., \& Kgathi, C. (2013). Predicting intentions to seek psychological help among Botswana university students: The role of stigma and help-seeking attitudes. Sage Open, 3(3), 2158244013494655.
Pinder, C. C. (1998). Work motivation in organizational behavior. Upper Saddle River, N.J: Prentice Hall, p. 363-388.

Rochlen, A. B., Blazina, C., \& Raghunathan, R. (2002). Gender role conflict, attitudes toward career counseling, career decisionmaking, and perceptions of career counseling advertising brochures. Psychology of Men E Masculinity, 3(2), 127-137. doi:10.1037/1524-9220.3.2.127

Rochlen, A. B., Mohr, J. J., \& Hargrove, B. K. (1999). Development of the attitudes toward career counseling scale. Journal of Counseling Psychology, 46(2), 196-206. doi:10.1037/0022-0167.46.2.196

Soliman, A. M. (1993). Choice of helpers, types of problems and sex of helpers of college students. International Journal for the Advancement of Counselling,16(2), 67-79.

Schwatken, S. (2014). Incongruence and attitudes toward career counseling (Order No. 3627454). Available from ProQuest Dissertations \& Theses A\&I. (1558874408). From http:/ / search.proquest.com/docview/1558 874408 ? accountid $=13158$

Vogel, D. L., Wade, N. G., \& Hackler, A. H. (2007). Perceived public stigma and the willingness to seek counseling: The mediating roles of self-stigma and attitudes toward counseling. Journal of Counseling Psychology, 54(1), 40-50. doi:10.1037/00220167.54.1.40

Wu, Y. L., Tsai, Y. L., \& Chen, C. W. (2014). Examining the experiences of career guidance, vocational self-concept, and selfperceived employability among science education majors in Taiwan. Journal of Baltic Science Education, 13(2). 